\title{
A Relational Sociological Study on the Effects of Uncertainties in the Case of Influenza in Turkey
}

\author{
Aytul Kasapoglu \\ Department of Sociology, Ankara University, Ankara, Turkey \\ Email: kasap@humanity.ankara.edu.tr
}

How to cite this paper: Kasapoglu, A. (2017) A Relational Sociological Study on the Effects of Uncertainties in the Case of Influenza in Turkey. International Journal of Clinical Medicine, 8, 618-630. https://doi.org/10.4236/ijcm.2017.811058

Received: February 10, 2017

Accepted: November 25, 2017

Published: November 28, 2017

Copyright $\odot 2017$ by author and Scientific Research Publishing Inc. This work is licensed under the Creative Commons Attribution International License (CC BY 4.0).

http://creativecommons.org/licenses/by/4.0/

\begin{abstract}
Health issues, especially global health issues, are important subjects of study for many sociologists. For example, the spread of influenza as a pandemic affects a large number of people and their emotions in terms of fear, becoming a social problem instead of a psychological issue. Because of uncertainties, what is happening and what people should do during global threats is not clear for many people generally and during pandemics specifically. The primary aim of this paper is to show the construction process of fear and risk by conducting a systematic review of former studies about the influenza that occurred in Turkey during the last 10 years. It is assumed that a combination of relational sociology and the sociology of disaster and development will provide an appropriate theoretical framework. In other words, $\mathrm{H}$. White and his uncertainty typology along with A.E. Collins' classification are both used to define the construction process of fear as a culture, starting with uncertainty and moving to alienation and finally normalization. Findings from this study, which are supported by N. Elias' and U. Beck's methodological considerations, revealed that uncertainties may lead to negative consequences, such as alienation. Due to conflicting information, people find themselves in a dilemma and they stop following norms and rules in terms of normlessness. Normlessness, as a subdivision of alienation along with meaningless, might result in negative actions, such as not getting vaccinated. Liminality, turning points and footing are also used to describe the construction process of fear and risk. Results also showed that over a 10-year period many things are normalized and people no longer panic as easily.
\end{abstract}

\section{Keywords}

Influenza, Relational Sociology, Uncertainties, Turkey 


\section{Introduction}

"We do not know what it is we do not know" is an important quote full of irony that was adopted by U. Beck from Socrates' famous saying, "I know that I know nothing" to describe the present situation [1]. Because we live in an era that is full of uncertainties, U. Beck called this era the "World Risk Society." Beck was a sociologist who was very interested in the irony of risks and wanted to investigate them. According to Beck, "risk means ambivalence and being in risk is the way of being and ruling in the world of modernity; being at global risk is the human condition at the beginning of the twenty-first century" [2]. Beck also argued that global risks represent a shock for all humanity because no one predicted such a development.

Sociologists have various options when they study risks in terms of uncertainties or ambivalence. Relational sociology is one such option that has recently gained significant popularity [3] [4]. This popularity is due in part to the abundant literature that claims relational sociology is a new paradigm superior to substantialist views, such as positivism and other mainstream sociologies [5]. This literature mostly claims that social reality is relational, and therefore we should focus on relations rather than things. Furthermore, these studies reject dualisms such as mind and body or agent and structure. Induction rather than deduction is preferred for logical reasoning, and they reject the idea of static social things and assume that reality is a continuous process. In addition, they are interested in daily life and its smallest units, such as "niches" and "survival units" [6]. In short, relationists are against essentialism and interested in reflexive sociology and studies on uncertainty.

Actually, dealing with uncertainties in the context of modernity has an important role in studies on relational sociology. During relational analysis, to overcome duality, inclusion of culture in the analysis, along with agent and structure, increases undetermined fields while decreasing determined social relations. Certainly, inclusion of culture in the analysis requires underlining social "distinctions" or differentiations in the "space of possibles" as mentioned by Bourdieu [7] [8]. According to $\mathrm{H}$. White, an eminent relational sociologist interested in uncertainty studies, "identities" are very important, and those identities are created by an uncertain social environment that is continuously changing. Under these uncertain circumstances, people need "footing" to guide their choices. In his famous study, "Identity and Control", White asserts that there is a need for uncertainty studies based on relational sociology [9].

It is obvious that there are close relationships among the concepts of risk, uncertainty and trust. However, it should also be noted that there are differences among them as well. For example, while we can fight risk through insurance mechanisms, we cannot fight uncertainties because there is no ultimate insurance for uncertainty. According to the neo-functionalist N. Luhmann [10], to trust someone under uncertain conditions means to take a risk. Indeed, there is a close link between trust and power. Because society is the arena of the power 
struggle, to become stronger, we should take risks and trust others.

According to White and his colleagues [11], there are two basic concepts to investigate, namely "ambage" and "ambiguity." Ambage refers to uncertainties about social relations, while ambiguity is used to explain the uncertainties in meanings. Actually, White also defines a third concept, namely "contingency," to refer to sudden and unexpected uncertainties.

According to the British sociologist A. Giddens [12], there are two kinds of disasters: natural and human made. Many disasters are human made and result in extraordinary material and human damage because of human beings' attitudes and behaviors. For example, people consciously or unconsciously expose themselves to high risk by constructing their houses in insecure areas. There are, however, arguments that make a distinction between disasters and hazards as well as risks and dangers. For example, Drabek [13] defined disaster as: "A disaster is an event in which a community undergoes such a severe loss to persons and/or property that the resources available within the community are severely taxed." According to Drabek, in contrast to a disaster, "a hazard is a condition with a potential for harm to the community or environment." Thus, the term disaster is used to refer to a specific event, such as the 2005 Bird flu pandemic, whereas the term hazard defines a class of threats, such as earthquakes or floods. Despite the differentiations, many sociologists continue to use the terms disaster and hazard interchangeably [13]. Because disasters and hazards reflect the risks and vulnerabilities of society, some sociologists assume that the emergency management of risks is of vital importance and can be defined as: "The process by which the uncertainties that exist in potentially hazardous situations can be minimized and public safety maximized." [13].

The ultimate goal, however, is to limit the costs of disasters by implementing several processes such as preparedness, response, recovery and mitigation that typically occur one after the other. These conceptual steps have also been used by many sociologists from different countries [14] [15] [16] [17] to emphasize the role of culture in emergency preparedness. In other words, similarities as well as differences regarding preparedness, response, recovery and mitigation patterns are investigated. According to a people centered approach, all hazards are unique in time and place and require specific treatment. As noted by Collins [18] the social organization of risk reduction can be differentiated into people centered approaches, health centered approaches, stakeholder rights and communications system based approaches, and these approaches can be implemented separately or by combining them.

According to Collins [18], social relations and systems of meaning are effective in disaster management and development. The topics of social networks, communication, accountabilities, and responsibilities all fall under the umbrella of social relations. Meanwhile, the values of both natural and human life, including mediation, hope and trust, are the elements of systems of meaning. In this context, uncertainty is the key concept in any disaster because, as discussed by Drabek [13], in many pre-and post-disaster situations, ambiguity in public 
announcements was the major complaint, including ambiguity in news reports as well as declarations by health authorities regarding what should or should not be done [19].

This paper assumes that a combination of White's conceptualization of uncertainties and Collins' classifications regarding social relations and meanings might be an appropriate theoretical framework in the case of infectious disease risk reduction.

\subsection{Research Problem and Objectives}

As argued by Beck [1] [2] in his "The Theory of World Risk Society," modern societies are shaped by new kinds of risks that are defined by three characteristics: de-localization, incalculableness and non-compensability. Because they are spatial, temporal and social, we cannot localize them. Ironically, we also do not know how to calculate risk and compensate our losses. As discussed by Beck, if the risks are non-compensable this means the risks are radicalized and fear and suspicion are increased. Actually, the concept of a "culture of fear," introduced to the literature by Furedi [20], is important to this study because fear as a culture, which is strengthened or developed by the media, has led people to feel more powerless and anxious under the threat of risks, especially health risks.

This study focuses on the increased uncertainties that lead to fear and alienation in the world and risk social conditions generally and in the case of pandemics experienced in Turkey in the last 10 years specifically.

Therefore, the following questions are presented:

1) Which pandemics were experienced in Turkey during the last ten years?

2) What uncertainties can be observed?

3) What consequences are observed over this 10-year span due to these uncertainties?

\subsection{Methodology}

The significance of this paper derives both from it's subject and theoretical framework that is a new approach so called "relational sociology".

This paper is primarily based on a "systematic review" - of two sociological studies carried out on influenza in the last 10 years in Turkey. According to Weed, "A systematic review is a review in which there is a comprehensive search for relevant studies on a specific topic." [21]. This study is also a "meta-interpretation" (Mills, 1959) used to overcome the limitations of a classical literature review by aiming critical evaluation and interpretative synthesis at existing studies [21].

The use of only two studies is also the main limitation of this meta-analysis. However, the other studies available were mostly statistical and were carried out by non-sociologists and therefore not appropriate for the meta-analysis. Furthermore, their data were not useful to complete a process based analysis according to Elias' methodology [22]. 
During the systematic review of the existing studies, the main principles of process based sociology developed by N. Elias, referred to as "methodological relationalism," were followed [22]. According to Elias, "process produced data" and mixed designed studies are more effective for sociological studies. Accepting the changing nature of the subjects, contrary to dichotomies and static subject relationships, is the main characteristic of Elias' methodology and has been found to be appropriate for this type of study.

Study 1: The Case of Avian Influenza in Turkey [23].

The first study is a quantitative study based on positivistic principles. Data were gathered in February 2006, immediately after warnings regarding the global outbreak of avian influenza H5N1 (popularly known as bird flu) were issued and the virus had been observed in Turkey. The survey sample comprised 488 people from all over Turkey; $56 \%$ were females and $44 \%$ were males. Responsible behavior to protect their health was the main dependent variable. Demographic factors (gender, age, education, and socio-economic status) and psycho-social variables (locus of control and fatalism) were all independent variables. Researchers also investigated policy suggestions at both the national and international levels based on the participants' views.

Study 2: Sociological Analysis of Risk and Fear Culture: The Case of H1N1 in Turkey [19].

The second study is a non-reactive study carried out based on realist constructionism, which combines positivistic and constructionist principles. Content analysis was performed during the pandemic on three newspapers between September 2009 and February 2010. The selection criteria for the newspapers were their political stances towards the government. Thus, the first newspaper is assumed to be representative of the government, the second is representative of an anti-government viewpoint, and the third is representative of an independent or neutral viewpoint. All three are analyzed using both qualitative and quantitative techniques.

\section{Findings}

In this section, comparisons of sociological studies (given in Table 1) on influenza are made using the conceptual framework briefly discussed in the introduction section. In other words, the theoretical framework of this paper is based on a combination of White [11] and Collins [18]. White, a relational sociologist,

Table 1. Summary of two studies.

\begin{tabular}{ccc}
\hline \multicolumn{1}{c}{ Name of studies } & $\begin{array}{c}\text { Date of } \\
\text { studies }\end{array}$ & Nature of studies \\
The Case of Avian Influenza & 2005 & $\begin{array}{c}\text { Quantitative and Qualitative; } \\
\text { Descriptive study }\end{array}$ \\
$\begin{array}{c}\text { Sociological Analysis of Risk and } \\
\text { Fear Culture: The Case of H1N1 in Turkey. }\end{array}$ & $2009-2010$ & Qualitative descriptive study \\
\hline
\end{tabular}


and Collins, an expert on the sociology of disasters and development, provide useful tools for the analysis of health risks in a process. Their focus on uncertainties and their classifications-social relations and system meanings-enabled us to demonstrate differentiation or change in a process.

\subsection{Ambage: Uncertainties in Social Relations}

To show the effects of uncertainties, it is assumed that ambage is a good starting point. According to White [11], ambage is one of the characteristics of uncertainties that can be observed in social relations. The word ambage has a similar meaning to winding, indirect and roundabout. From a relational sociological point of view, it indicates how roles are performed or forced to be performed. It also shows us how social relations are constructed and ended. As noted by Goffman [24], there are role expectations and, certainly, some people avoid performing those roles. Thus, ambage is a concept primarily used to explain or describe the cases when those roles are not performed.

In the case of the avian influenza, researchers used "locus of control" as an independent variable [23] [25]. According to Kasapoglu and Ecevit "locus of control" can be divided into two types: internal and external [26] [27]. An internal locus of control refers to people who do not expect things from powerful others, such as the state or God. It was measured using the following statement: "The state should bear the greatest responsibility for the problem."Lower scores are indicative of a higher internal locus of control, while higher scores are indicative of an external locus of control.

For the variable of locus of control, statistical analysis showed that women's internal locus of control was lower than men's. In other words, women's expectations from the state to deal with health risks, especially regarding avian influenza, were higher (48\%) than those of men (38\%).

These findings show that during the avian influenza pandemic, social roles and expectations were uncertain because many people were confused and did not want to carry his/her responsibilities but wanted to transfer those responsibilities to powerful others, such as the state. Notably, as education level increased, internal locus of control increased, and this increase can be interpreted as showing that education is an important variable for certainty and uncertainty studies.

In the case of the second study [19] on HINI, commonly called the "swineflu," in Turkey, the researcher found that the most important uncertainty was that of vaccination. From the beginning, there was controversial news about the vaccination. Interestingly, there was even a conflict between political authorities. At the beginning of the pandemic, the Ministry of Health declared that there was a high risk of catching HINI and that vaccination was necessary, starting with health personnel. The Minister of Health was vaccinated in front of the public, and his vaccination was highly publicized in the news and media. Soon after, however, the Prime Minister began to speak out against the vaccination. At the 
same time, there were also news reports from the international media that question quality of vaccine. According to the news, there were differences between the vaccines given to the public and those given to politicians. In the midst of these discussions, the Prime Minister announced that he would not be vaccinated. As mentioned earlier, the researcher reviewed three different newspapers and found that the anti-government newspaper was full of news covering the controversy between the Minister of Health and the Prime Minister, while the newspaper that supported the government claimed that the implementation of vaccinations continued to be successful. Soon after, news about the drop in vaccinations began to appear in the newspaper of anti-government. All this news is interpreted by the researcher as a loss of trust in political authorities as well as in health experts.

\subsection{Ambiguity: Uncertainties in Meanings}

According to White and his colleagues [11], ambiguity is an uncertainty that can be observed in a cultural context as values. Ambiguity is also related to rules and norms because rules and norms reflect the meaning of a situation. It is also helpful to understand and evaluate what specific sign belongs to what rule. Ambiguity is different from ambage because it does not force people to obey rules. According to White, we communicate by using signs. Therefore, signs and symbols help to reduce the level of ambiguity. Actually, ambage and ambiguity are two dynamics that follow each other.

In the avian influenza study, researchers wanted to evaluate participants' values by using a fatalism variable. The statement: "What is happening is divine providence and we cannot do anything about it" was used to measure the fatalism variable [26]. High scores of fatalism are interpreted as an indicator of traditional culture.

Findings in this study revealed that fatalists believe that God knows everything, which is in accordance with former research [28]. In Turkey, the majority of people are Muslim and believe in God. Concerning fatalism, as the educational level of participants increased, their fatalistic values decreased. The percentage of participants who highly agreed with fatalism was the lowest among university graduates and high income participants who hold more modern and rational values than traditional values. There were also negative correlations between knowledge and fatalist attitudes, internal locus of control and fatalist attitudes, and fatalist attitudes and responsible behavior. These findings indicate that participants faced ambiguity because participants who had higher levels of education did not believe in the positive effects of vaccination and did not get vaccinated. Other people who were less educated, however, believed that God would save them from all harms and that they did not need a vaccination.

The second study on the H1NI pandemic (2009/2010) revealed that there are many factors that lead to uncertainty generally and ambiguity specifically. For example, the majority of people were worried about whether the vaccination was forbidden by Islam, and they questioned religious authorities on this issue. Dur- 
ing the period of Pilgrimage, many believers also believed that the H1N1 pandemic could not reach Saudi Arabia. Therefore, they exposed themselves to risk by flying to Mecca. Another conflict arose over hand kissing. During Ramadan, religious authorities declare that people should kiss hands to show respect to elder people. However, at the same time, the Ministry of Health announced that because of the HINI flu, people should stop touching each other, including kissing hands. According to the news reports that were analyzed, there were also conflicting views regarding the use of the vaccine. This was especially true after rumors spread about the World Health Organization (WHO) and vaccine producers. As a result, people lost their confidence in both national and international health authorities. Furthermore, the conflicting news resulted in the rise of fear and uncertainty.

\subsection{Recent Statistics}

In the 2014-2015 influenza season, the Ministry of Health reported that 43 citizens of the Republic of Turkey died due to H1N1. There were also seven deaths from Influenza B and seven deaths from H3N2. The total number of deaths was 57 , and the majority of those who died were adults over 65 years of age with chronic pulmonary and cardiovascular systemic diseases. Children and adolescents undergoing treatment for immune system problems or acetyl salicylic acid treatments were also defined as risk groups. In the current season (2015-2016), there is, again, news about HINI in Turkey. In January 2016, it was reported as: "Shock: Swine Flu is Back". There was also a news report from Iran in December 2015 that stated: "There is Swine Flu in the Neighborhood: 33 Deaths". By December 2015 updated reports by the World Organization for Animal Health declared that avian influenza was present in Turkey and Romania. There are also news reports stating that approximately 50 deaths have occurred in Russia as of January 2016.

According to the Ministry of Health, there is no pandemic in Turkey because the H1N1 virus is included in the prevailing vaccines. However, in the case of a mutation, the risk will be increased because the mutated version of the virus will be unknown and therefore will not be included in vaccines. At present, there have been 57 official deaths from H1N1 in Turkey. It has been repeatedly announced that there is nothing to cause panic and that people can recover from influenza by getting rest and healthy nutrition. The majority of deaths have occurred in the more complicated cases, such as people suffering from COPD (Chronic Obtructive Pulmonary Disease) and blood diseases. Recently, many health programs have appeared on TV to provide information about natural ways to strengthen the body instead of taking medicine. These programs also continuously inform elderly people who are over 65 to get vaccinated.

\section{Discussion}

In the sociological study of disaster uncertainty, risk, fear and trust are the main concepts that have close relationships with each other. According to F. Furedi 
[20], the only thing we have to fear is the culture of fear itself. His primary focus is on how our attitudes and behaviors are determined by a regime of uncertainty. According to him, todays' sociological writings use fear and risk interchangeably because fear is associated with significant threats, such as AIDS, flu pandemics, and global warming, as well as the quiet fears of daily life. Furedi also claims that the focus in the risk literature is on risk rather than fear, and fear does not receive the attention and respect that it deserves. Norbert Elias is an exception who has recognized the role of fear in his studies. For example, in his book Civilization Process [29], he underlined the importance of fear by defining it as a mechanism that facilitates the transmission of society to individual psychological functions. He believed that to have a civilized character people should internalize their fears.

Although there were not many sociological studies to review, these two studies [19] [23] showed that examples of uncertainties in social relations (ambage) and meanings (ambiguity) were abundant and can be demonstrated by using scientific data. In addition to ambage and ambiguity, some other basic concepts developed by White [9] [11], including "liminality", "turning points", and "footing", have also been found to be useful in describing the process of a pandemic.

For example, in the case of HINI (2010), people felt squeezed between two authoritative pressures: the Minister of Health pushing them to get vaccinated and the Prime Minister denying the vaccine's effectiveness. Therefore, the position of the public was ambiguous or in "liminality" as defined by White. For lay people, it was not easy to make a decision about vaccination for themselves and their children because health and political issues were interwoven.

The main "turning point" in this process was the Prime Minister's declaration that "he has never believed that there is a pandemic, and he will not get vaccine." Soon after his speech, there were also news reports regarding corruption in the WHO. It appears that the Prime Minister learned what was happening in the vaccine sector and, for the sake of the nation, shared his views regarding the vaccine. It was also observed that the discourse regarding the pandemic and vaccination policy was changed on the websites of the Ministry Health. One high level bureaucrat stated that the stocked vaccines were sold to other countries that needed them. With this explanation, the government attempted to create the image that they are sensitive to the needs of the people when they spend money and not in cooperation with vaccine producers who create false pandemic risks to sell their expensive vaccines.

The high fatalism and low internal control scores during the H5N1 pandemic in 2006 and the attitudes and behaviors towards vaccination during the H1N1 pandemic in 2010, demonstrate that people need "footing". Footing is another concept used by White. To cope with uncertainties, people need to be able to control the uncertainties. By using the term "identity" instead of "individual" or "actors", White wanted to overcome agent-structure duality while pointing out the need for footing as trust. According to White, people look for mechanisms to 
feel secure. In the case of the 2010 HINI pandemic in Turkey, the Prime Minister, as an example of external control, helped people make up their minds and feel secure through his speeches. It could also be argued that there was a power struggle between national and international authorities at both the inter- and intra-organizational levels. Furthermore, to trust someone or something also means to take risks, as noted by N. Luhmann [9].

This study also shows that increases in uncertainties lead to alienation, and people who face dilemmas may stop obeying rules and norms. Normlessness and meaninglessness, as the sub forms of alienation [29] [30] [31], develop and influence people's behaviors. In other words, uncertainty negatively affected people's attitudes and behaviors generally and towards vaccination specifically. These findings are in accordance with other studies that have been carried out in Turkey [32] [33] [34].

Finally, the findings related to the present influenza that started in December 2015 and has continued until the beginning of 2016 show that people are calm and do not react severely. This reaction stems from their previous experiences with HINI, which convinced them that there is no reason to panic. Nonetheless, there have been some deaths ( 57 deaths out 400 influenza case) but most of those were elderly and suffered from other serious chronic diseases, such as cancer or coronary heart disease. This relative calmness can be interpreted as the result of the process of the "normalization" of uncertainties. People now understand that if they follow hygienic rules and rest they will recover quickly. In addition, their experiences with the benefits of natural foods and herbs were also helpful with normalization, which seems to be the final step of this process.

\section{Conclusions}

According to Furedi [20], Elias was right when he said that "the strength, kind and structures of the fears and anxieties that smolder or flare in the individual never depend solely on his own 'nature" [35]. Rather, they are "always determined, finally by the history and the actual structure of his relations to other people". This point is especially important in this study because its theoretical framework is based on relational sociology and the view that "the impact of fear is determined by the situation people find themselves in, but it is also, to some extent, the product of social construction" [29].

The findings of this systematic review revealed that the concept of uncertainty and its types or characteristics as pointed by White [10], along with other concepts introduced in his study, namely Identity and Control [9], are important to understand the construction of fear or risk as a process over the last 10 years.

This study, which is based on the combination of relational sociology and the sociology of disasters, showed that we should focus on processes rather than things if we want to draw a more realistic picture of important social phenomenon such as the H5NI and HINI pandemics.

As noted by Collins [18], policy suggestions in Turkey should be bottom-up 
instead of top-down. Therefore, community involvement and early action are worth mentioning [36]. Furthermore, the following suggestions are also important: 1) Multilevel planning; 2) National coordination among the health and agricultural sectors, including veterinary sciences and education; and 3) International coordination at all levels to provide equity, which is also shared by the WHO [37] [38].

Risk assessments and communication are also very important in implementing early warning systems. To make plans to reduce risks, health authorities and politicians should collaborate with sociologists as well as other life scientists. Disaster resilience and human security are closely related to social, economic and emotional wellbeing. Thus, if we want to live in the world risk society as noted by Beck [2], health security and risk management, including integrated food and livelihood security, during infectious disease pandemics are the main subjects to investigate based on the relational sociological perspective of White and the process produced data of Elias. Furthermore, we should also avoid "methodological nationalism" because it prevents sociology from understanding the dynamics, conflicts, ambivalences, and ironies of the world risk society. Because there are time and space differences among cases in term of the "space of possibles" [7] [8], each case requires its own solution. This is also why we need bottom-up rather than top-down approaches.

\section{References}

[1] Beck, U. (1998) What Is Globalization? Polity Press, Cambridge.

[2] Beck, U. (2006) Living in the World Risk Society. Society and Economy, 3, 329-345. http://dx.doi.org/10.1080/03085140600844902

[3] Depelteau, F. (2008) Relational Thinking: A Critique of Co-Deterministic Theories of Structure and Agency. Sociological Theory, 26, 51-73.

http://dx.doi.org/10.1111/j.1467-9558.2008.00318.x

[4] Depelteau, F. and Powell, C. (2013) Applying Relational Sociology: Relations, Networks and Society. Palgrave \&Macmillan, New York. https://doi.org/10.1057/9781137407009

[5] Donati, P. (2011) Relational Sociology: A New Paradigm for Social Sciences, Ontological Explorations. Routledge, London.

[6] Kivinen, O. and Piioinen, T. (2013) Human Transaction Mechanisms in Evolutionary Niches: A Methodological Relationalist Standpoint. In: Depelteau, F. and Powell, C., Eds., Applying Relational Sociology: Relations, Networks and Society, Palgrave, New York, 83-101. http://dx.doi.org/10.1057/9781137407009.0008

[7] Bourdieu, P. (1977) Outline of a Theory of Practice. Cambridge UP, Cambridge. http://dx.doi.org/10.1017/CBO9780511812507

[8] Bourdieu, P. (1984) Distinctions: A Social Critiques of the Judgement of Taste. Harvard UP, Cambridge.

[9] White, H.C. (1992) Identity and Control: A Structural Theory of Social Action. Princeton UP, Princeton.

[10] Luhmann, N. (1979) Trust and Power. Wiley, Chichester.

[11] White, H.C., Godart, F.C. and Thiemann, M. (2013) Turning Points and the Space 
of Possibles: A Relational Perspective on the Different Forms of Uncertainty. In: Depelteau, F. and Powel, C., Eds., Applying Relational Sociology: Relations, Networks and Society, Rave, New York, 137-154. http://dx.doi.org/10.1057/9781137407009.0010

[12] Giddens, A. (1998) Risk Society: The Context of British Politics. In: Franklin, J., Ed., Politics of Risk Society, Polity Press, Cambridge.

[13] Drabek, T.E. (2005) Sociology, Disasters and Emergency Management: History, Contributions and Future Agenda. In: McEntire, D.A., Ed., Disciplines, Disasters and Emergency Management, Emergency Management Center, Maryland.

[14] Parker, D.J. (2000) Floods. Routledge, London.

[15] Britton, N.R. and Clapham, K. (1991) Annotated Bibliography of Australian Hazards and Disaster Literature, 1989-1989. University New England, New South Wales.

[16] Porfiriev, B. (1998) Disaster Policy and Emergency Management in Russia. Nova Science Publishers, New York.

[17] Quarantelli, E.L. and Pelanda, C., Eds. (1989) Proceedings of the Italy-United States Seminar on Preparations for, Responses to, and Recovery from Major Community Disasters, Newark, 5-10 October1986, Disaster Research Center, University of Delaware, Emergency Management Center, Maryland.

[18] Collins, E.A. (2009) Disaster and Development. Routledge, London.

[19] Akbal, A. (2010) Sociological Analysis of Risk and Fear Culture: The Case of H1N1 in Turkey. Unpublished Master Thesis, Ankara University Institute of Social Sciences.

[20] Furedi, F. (1997) Culture of Fear. Continuum Press, London.

[21] Weed, M. (2005) "Meta Interpretation": A Method for the Interpretive Synthesis of Qualitative Research. Forum Qualitative Sozialforschung/ Forum: Qualitative Social Research, 6, Article 37. http://nbn-resolving.de/urn:nbn:de:0114-fqs0501375

[22] Baur, N. and Ernst, S. (2011) Towards a Process-Oriented Methodology: Modern Social Science Research Methods and Norbert Elias's Figurational Sociology. The Sociological Review, 59, 117-139. http://dx.doi.org/10.1111/j.1467-954X.2011.01981.x

[23] Kasapoglu, A., Odabas, Y. and Kaya, N. (2009) The Case of Avian Influenza in Turkey. European Societies, 11, 495-510. http://dx.doi.org/10.1080/14616690802531926

[24] Goffman, E. (1969) Stigma: Notes on Management of Split Identity. Prentice Hall, Englewood Cliffs.

[25] Kasapoglu, A. and Ecevit, M. (2001) Depremin Sosyolojik Arastirmasi. Sosyoloji Derneği, Ankara.

[26] Kasapoglu, A. and Ecevit, M. (2003) Impact of East Marmara Earthquake in Turkey. Population and Environment, 24, 339-358. http://dx.doi.org/10.1023/A:1022453722574

[27] Ecevit, M. and Kasapoglu, A. (2002) Demographic and Psychosocial Features and Their Effects on the Survivors of the 1999 Earthquake in Turkey. Social Behavior and Personality, 30, 195-202. http://dx.doi.org/10.2224/sbp.2002.30.2.195

[28] Karanci, N., Alkan, N., Akşit, B., Sucuoglu, H. and Balta, E. (1999) Gender Differences in Psychological Distress, Coping, Social Support and Related Variables Following Dinar, Turkey Earthquake. North American Journal of Psychology, 1, 189204.

[29] Elias, N. (2000) The Civilizing Process: Sociogenetic and Psychogenetic Investigations. In: Jephcott, E., Dunning, E., Goudsblom, J. and Mennel, S. (Trans.), Black- 
well, Singapore.

[30] Seeman, M. (1959) On the Meaning of Alienation. American Sociological Review, 24, 783-791. http://dx.doi.org/10.2307/2088565

[31] Seeman, M. (1991) Alienation and Anomie. In: Robinson, J., Shaver, P.R. and Wrightsman, L.S., Eds., Measures of Social Psychological Attitudes, Michigan University Press, East Lansing, 291-371.

https://doi.org/10.1016/B978-0-12-590241-0.50011-3

[32] Kaya, N.C., Kasapoglu, A. and Odabas, Y. (2011) Do Global Threats Lead to Awareness or Alienation? The Case of Avian Influenza in Turkey. Ankara Üniversitesi Çevre Bilimleri Dergisi, 1, 29-35.

[33] Odabaş, Z.Y. and Ertong, G. (2012) Social Effects of Disasters as Actants: A Comparison of 1999 Marmara Earthquake, Turkey and 2004 Tsunami, Indonesia. Ankara Üniversitesi Çevre Bilimleri Dergisi, 3, 47-54.

[34] Odabas, Z.Y. and Ertong, G. (2011) Social Effects of Avian Influenza: Comparisons of Turkey and Indonesia. Sosyoloji Araştırmaları Dergisi, 14, 193-212.

[35] Elias, N. (1977) Towards a Theory of Social Process. Collected Works, Vol. 16, UCD Press, Dublin.

[36] Kasapoğlu, A., Mileti, D. and Deflem, M. (2007) Is the United States Ready for Future Catastrophes? Estimating the Effectiveness of Organizations for Hazard Mitigation since 9/11. Homeland Security Journal, 1, 1-14.

[37] WHO (2006) Making Preparation Count: Lessons Learned from the Avian Influenza Outbreak in Turkey. World Health Organization Publication, Denmark.

[38] Kasapoglu, A., Ecevit, Y. and Ecevit, M. (2004) Impact of Several Worry Factors on Responsible Behavior: The Case of 1999 Earthquake in Turkey. International Journal of Mental Health, 33, 13-30. 